\title{
Early Fitting For CI Patients
}

\author{
Ayman Kamal* \\ Clinical Audiology \& Therapy of Hearing School of Advanced Education Research and Accreditation, Universidad Isabel I-Spain, Spain
}

Submission: July 06, 2017; Published: July 12, 2017

*Corresponding author: Ayman Kamal, Clinical Audiology \& Therapy of Hearing School of Advanced Education Research and Accreditation, Universidad Isabel I-Spain, Spain, Tel: 966559 961245; Email: aymanfakerkamal@gmail.com

\section{Editorial}

Fitting of cochlear implants patient is one of the important phases the patient is facing during his journey of cochlear implantation. And the first step of this phase is called the "First Switch on or Activation session ". The standard time difference between the surgery and this session was agreed worldwide to be between 4 - 6 weeks as a standard time in order to give time for healing process of the wound and the patient get relaxed after the surgery. However in these days clinics begin to decrease the time between the surgery and the activation session, in order to give the patient an earlier electric stimulation with their cochlear implants which -as per some speech therapists - accelerate the rehabilitation time especially for young children. To accurately study the best time difference we have to mention the factors affecting the whole process which are

Healing process: It is considered as a surgical factor and depends mainly on the patient history and the incision size the smaller the incision, the faster recovery and healing time for the wound.

Patient's age: It is an important factor to consider as for adults it would be easier for them to decide when they are tolerant to go for the activation session while in case of children it actually depends on their parents who are usually extremely excited to do the activation as soon as possible.

Psychological Status: To have an excited patient waiting for the activation session will really help a lot during the fitting ,but here is the question : Should we better give him some time waiting the activation to increase his excitement or fit the processor as early as possible to give him a fruitful results considered as a motivation for him. Is the early activation act as a motivation or depression factor? In another way, If the patient especially the children, correlate their paining experience after the surgery by the electric stimulation from the processor, this will be reflected as hatred feeling for them toward the device or not?
Technical factors: As it is so clear that after implantation the implant impedances will vary a lot during the first days ,so is this will affect the sound perception for the patient or not? , this also another question also the magnet power will be affected by the distance between the implant and the skin, Is this will change the magnet power or not?

A study in King Saud University [1] which considered as the first center in the world to apply the "One Day Fitting Protocol" for children and adults, the study was applied on Twenty-nine participants (11 males, 18 females) in the age range of 1 to 42 (average of 5 years), they looked for all the previous mentioned factors and the results was as the following: Regarding the healing process and the infection rate, there were no serious complications reported postoperatively. However, four patients (about 14\%) exhibited mild wound swelling at one-day postsurgery.

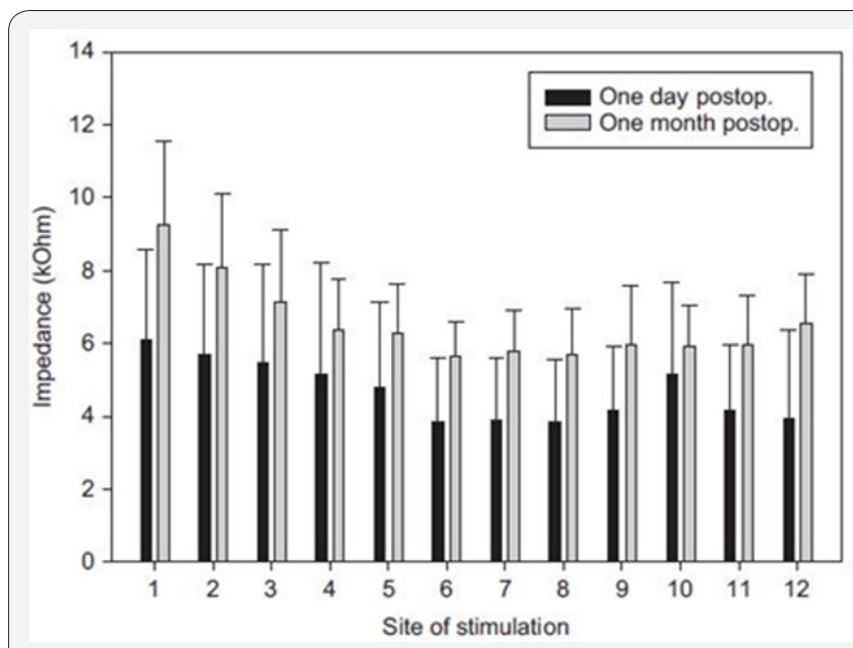

Figure 1: Impedances in all 12 channels.

As mentioned before, the average age of the 29 participant is 5 years and this show that most of the patients are children and as mentioned in the study none of the patients rejected 
the speech processor or complained of pain during the fitting process. Also most of the patients used the standard magnet power. Regarding the impedances, results of this study showed a significant difference between the one-day and the one-month testing of impedance were significant for all electrodes $(p<0.01)$ with the exception for electrode 10 . Specifically, electrode impedance values were higher for the one month measurements than those measured at one day after the surgery (Figure 1).
Therefore it is good topic to look for especially both parties have good points to prove whether they are with or against the early fitting.

\section{References}

1. Hagr A, Garadat SN, Al-Momani M, Alsabellha, RM, Almuhawas FA (2015) Feasibility of one-day activation in cochlear implant recipients. International Journal of Audiology 54: 323-328.

\section{Your next submission with Juniper Publishers will reach you the below assets}

- Quality Editorial service

- Swift Peer Review

- Reprints availability

- E-prints Service

- Manuscript Podcast for convenient understanding

- Global attainment for your research

- Manuscript accessibility in different formats

( Pdf, E-pub, Full Text, Audio)

- Unceasing customer service

Track the below URL for one-step submission https://juniperpublishers.com/online-submission.php 